\title{
Effect of Blast Furnace Slag Powder and Fly Ash on Durability of Concrete Mixed with Seawater
}

\author{
N. Otsuki, T. Nishida, C. Yi, and T. Nagata \\ Department of International Development Engineering, Tokyo Institute of Technology \\ H. Ohara \\ JGC Corporation
}

\begin{abstract}
According to the report of the United Nations, it is said that two-third of world population would be influenced by water shortage before 2050. To use fresh water effectively, the usage of seawater in concrete industry seems imperative. However, the usage of seawater as concrete material is prohibited in almost all the standards or specifications around the world. In this article, the usage of seawater as a material of concrete based on the results of experimental works and deterioration prediction was discussed. Especially, the effects of by-products such as blast furnace slag or fly ash on the durability of concrete mixed with seawater were evaluated. In the experimental works, the measurements of the material diffusivity/permeability such as chloride ion diffusivity, carbonation rate, and oxygen permeability in concrete/mortar were conducted. Also, the time-dependent changes of corrosion rate of steel bar embedded in mortar were periodically measured. At the same time, immobilization ability of cement matrix and corrosion threshold chloride ion content of steel bar were evaluated. Based on the above data, the initiation and propagation periods were predicted, and the durability of concrete mixed with seawater and the effectiveness of adding by-products were discussed. Based on the results of the present article, it was said that the period before the generation of cracks due to steel corrosion in concrete mixed with seawater was almost same with that with fresh water under severe chloride attack environment. Also, it could be concluded that the addition of blast furnace slag powder or fly ash might contribute significantly to the corrosion resistance of steel bar as well as low penetrability of materials.
\end{abstract}

\section{INTRODUCTION AND OBJECTIVES}

According to the report of the United Nations (WMO, 1997), it is said that two-third of world population would be influenced by water shortage before 2050 . To use fresh water effectively, the usage of seawater in concrete industry seems imperative. However, the usage of seawater as concrete material is prohibited in almost all the standards or specifications around the world.

In this century, modern standards and specifications are going to be "performance based", then if lifetime serviceability or limit states are guaranteed within specified years, concrete structures can be designed even mixed with seawater and/or cured in seawater. Then the question is what kind of limit states will be required in the lifetime of the structure.

As for limit states, some choose "no corrosion at all" condition, and the other choose "no cracks even after corrosion starts".

From the aforementioned background, the main objective of this article is "to show the possibility of using seawater with Blast Furnace slag (BFS) or
Fly Ash (FA) as mixing water in concrete in some conditions", and the subobjectives, which are related to investigate the effect of BFS, FA, and seawater, are shown as follows:

(1) investigation of the diffusivity/penetrability of materials,

(2) investigation of the corrosion rates of steel bars,

(3) investigation of the corrosion threshold chloride ion content,

(4) lifetime prediction against chloride attack and carbonation, and

(5) discussion of the effect of BFS and FA with seawater.

\section{EXPERIMENTAL WORKS}

In this article, the outline of specimens and experimental methods are introduced.

\subsection{Outline of specimens}

Specimens for chloride attack and carbonation were fabricated. 
Two types of specimen, namely nonreinforced cylinder $(\varphi 100 \mathrm{~mm} \times 200 \mathrm{~mm})$ concrete specimen and prism shape $(40 \mathrm{~mm} \times 40 \mathrm{~mm} \times 160 \mathrm{~mm})$ mortar specimen, were used for investigations. Tables 1 and 2 show the mixing proportion of concrete and mortar specimens, respectively. As cement material, OPC and OPC with BFS at 4055 , and $70 \%$ of replacement ratio and OPC with FA (Class F) at 10 and $30 \%$ of replacement ratio were used as cement. Artificial seawater, designed according to Table 3, and tap water were used as mixing water. The water to binder ratio was 0.5 and 0.7 for both types of specimens. The round steel bars of SR235 $(\varphi 13 \mathrm{~mm} \times 100 \mathrm{~mm})$ were embedded in mortar specimens with $10 \mathrm{~mm}$ covering depth.

Moist curing for concrete specimens and a week of immersion curing for mortar specimens were implemented, respectively. The moist curing periods were 5 days for OPC concrete specimen and 7 days for BFS concrete specimens. Immersion water was the same type of mixing water of each specimen. Then, except under surface of specimens at casting used for exposure surface, concrete and mortar specimens were coated with epoxy resin before exposure.

\subsection{Measurements}

In this article, the lifetime of concrete mixed with seawater is calculated with the outline of lifetime prediction as shown in Figure 1.

Against chloride attack, chloride ion diffusivity and corrosion threshold chloride ion content are needed to calculate the initiation period and corrosion rate of steel bars; the conditions for cracking are needed to calculate the propagation period.

Against carbonation, carbonation coefficient is needed to calculate the initiation period.

For corrosion threshold chloride ion content, the time-dependent changes of corrosion currents of steel bars are needed. For corrosion rates of steel bars, oxygen permeability is needed. To explain the effect of BFS and FA, the immobilization abilities are required.

\subsubsection{Chloride ion diffusivity}

In this article, concrete specimens were submerged into artificial seawater. After 4 months of exposure, the distributions of total chloride content at different

Table 1. Mixing proportion of concrete specimens.

\begin{tabular}{|c|c|c|c|c|c|c|c|c|c|c|c|c|c|}
\hline \multirow{3}{*}{ No. } & \multirow{3}{*}{ W/C } & \multirow{3}{*}{$\begin{array}{c}\text { Mixing } \\
\text { water }\end{array}$} & \multirow{3}{*}{$\begin{array}{l}s / a \\
(\%)\end{array}$} & \multicolumn{8}{|c|}{ Unit of weight } & \multirow{3}{*}{$\begin{array}{l}\text { Slump } \\
(\mathrm{cm})\end{array}$} & \multirow{3}{*}{$\begin{array}{l}\text { Air } \\
\text { (\%) }\end{array}$} \\
\hline & & & & \multicolumn{6}{|c|}{$\left(\mathrm{kg} / \mathrm{m}^{3}\right)$} & \multicolumn{2}{|c|}{ C x (\%) } & & \\
\hline & & & & $\mathbf{W}$ & C & BFS & FA & S & G & AW & $\mathrm{AE}$ & & \\
\hline 0.5-OPC-T & & \multirow{7}{*}{ Tap water } & \multirow{12}{*}{42} & \multirow{12}{*}{171} & 342 & 0 & 0 & 764 & 1,052 & 1.4 & 0.017 & 5.00 & 3.0 \\
\hline $0.5-B 40-\mathrm{T}$ & & & & & 205 & 137 & 0 & 748 & 1,047 & 1.4 & 0.021 & 10.5 & 3.0 \\
\hline 0.5-B55-T & & & & & 154 & 188 & 0 & 748 & 1,044 & 1.2 & 0.021 & 7.50 & 2.9 \\
\hline 0.5-B70-T & & & & & 103 & 239 & 0 & 748 & 1,041 & 1.2 & 0.021 & 8.00 & 2.8 \\
\hline 0.5-FA10-T & & & & & 308 & 0 & 34 & 761 & 1,047 & 1.4 & 0.017 & 11.0 & 1.8 \\
\hline $0.5-\mathrm{FA} 30-\mathrm{T}$ & & & & & 239 & 0 & 103 & 754 & 1,036 & 1.4 & 0.017 & 10.0 & 1.6 \\
\hline $0.5-\mathrm{OPC}-\mathrm{S}$ & 0.5 & & & & 342 & 0 & 0 & 764 & 1,052 & 1.4 & 0.017 & 7.00 & 3.0 \\
\hline $0.5-B 40-S$ & & \multirow{5}{*}{$\begin{array}{l}\text { Artificial } \\
\text { seawater }\end{array}$} & & & 205 & 137 & 0 & 748 & 1,047 & 1.4 & 0.021 & 13.0 & 3.1 \\
\hline $0.5-B 55-S$ & & & & & 154 & 188 & 0 & 748 & 1,044 & 1.2 & 0.021 & 10.5 & 3.1 \\
\hline $0.5-B 70-S$ & & & & & 103 & 239 & 0 & 748 & 1,041 & 1.2 & 0.021 & 11.5 & 3.0 \\
\hline $0.5-F A 10-S$ & & & & & 308 & 0 & 34 & 761 & 1,047 & 1.4 & 0.017 & 9.50 & 4.0 \\
\hline $0.5-\mathrm{FA} 30-\mathrm{S}$ & & & & & 239 & 0 & 103 & 754 & 1,036 & 1.0 & 0.021 & 8.00 & 2.1 \\
\hline 0.7-OPC-T & \multirow{12}{*}{0.7} & \multirow{7}{*}{ Tap Water } & \multirow{12}{*}{46} & & 249 & 0 & 0 & 870 & 1,018 & 1.0 & 0.010 & 7.50 & 3.1 \\
\hline 0.7-B40-T & & & & & 149 & 99 & 0 & 868 & 1,013 & 1.0 & 0.010 & 7.50 & 2.4 \\
\hline 0.7-B55-T & & & & & 112 & 137 & 0 & 865 & 1,013 & 1.0 & 0.011 & 10.0 & 2.6 \\
\hline 0.7-B70-T & & & & & 75 & 174 & 0 & 865 & 1,010 & 0.7 & 0.011 & 6.00 & 2.5 \\
\hline 0.7-FA10-T & & & & & 308 & 0 & 34 & 761 & 1,047 & 1.4 & 0.017 & 11.0 & 1.8 \\
\hline 0.7-FA30-T & & & & & 239 & 0 & 103 & 754 & 1,036 & 1.0 & 0.020 & 10.0 & 1.6 \\
\hline $0.7-\mathrm{OPC}-\mathrm{S}$ & & & & 174 & 249 & 0 & 0 & 870 & 1,018 & 1.0 & 0.010 & 3.50 & 3.8 \\
\hline $0.7-B 40-S$ & & \multirow{5}{*}{$\begin{array}{l}\text { Artificial } \\
\text { seawater }\end{array}$} & & & 149 & 99 & 0 & 868 & 1,013 & 1.0 & 0.010 & 4.50 & 3.1 \\
\hline 0.7-B55-S & & & & & 112 & 137 & 0 & 865 & 1,013 & 1.0 & 0.011 & 10.0 & 3.5 \\
\hline 0.7-B70-S & & & & & 75 & 174 & 0 & 865 & 1,010 & 0.7 & 0.011 & 6.50 & 4.5 \\
\hline 0.7-FA10-S & & & & & 308 & 0 & 34 & 761 & 1,047 & 1.4 & 0.017 & 9.50 & 4.0 \\
\hline $0.7-F A 30-S$ & & & & & 239 & 0 & 103 & 754 & 1,036 & 1.0 & 0.020 & 8.00 & 2.1 \\
\hline
\end{tabular}

W: water (fresh water or seawater), C: ordinary Portland cement (density: $3.14 \mathrm{~g} / \mathrm{cm}^{3}$, surface area: $3210 \mathrm{~cm}^{2} / \mathrm{g}$ ), BFS: blast furnace slag [density: $2.89 \mathrm{~g} / \mathrm{cm}^{3}$, surface area: $4310 \mathrm{~cm}^{2} / \mathrm{g}$, activity index (28 days): $94 \%$ ], FA: fly ash Class F [density: $2.23 \mathrm{~g} / \mathrm{cm}^{3}$, surface area: $3630 \mathrm{~cm}^{2} \mathrm{~g}$ activity index (28 days):84\%], S: natural river sand density (SSD): $2.60 \mathrm{~g} / \mathrm{cm}^{3}$, water adsorption ratio: $2.20 \%$, F.M. 2.59 Seawater: artificial seawater mixed with chemicals shown in Table 1. 
Table 2. Mixing proportion of mortar specimens.

\begin{tabular}{|c|c|c|c|c|c|c|c|}
\hline \multirow{2}{*}{ No. } & \multirow{2}{*}{$W / C$} & \multirow{2}{*}{$\begin{array}{l}\text { Mixing } \\
\text { water }\end{array}$} & \multicolumn{5}{|c|}{ Unit of weight $\left(\mathrm{kg} / \mathrm{m}^{3}\right)$} \\
\hline & & & $\mathbf{W}$ & C & BFS & FA & $\mathbf{S}$ \\
\hline $0.5-\mathrm{OPC}-\mathrm{T}$ & \multirow{12}{*}{0.5} & \multirow{7}{*}{$\begin{array}{l}\text { Tap } \\
\text { water }\end{array}$} & 311 & 622 & 0 & 0 & 1,245 \\
\hline $0.5-B 40-\mathrm{T}$ & & & 305 & 366 & 244 & 0 & 1,220 \\
\hline 0.5-B55-T & & & 303 & 272 & 333 & 0 & 1,210 \\
\hline $0.5-B 70-\mathrm{T}$ & & & 301 & 181 & 421 & 0 & 1,200 \\
\hline $0.5-\mathrm{FA} 10-\mathrm{T}$ & & & 312 & 562 & 0 & 62 & 1,249 \\
\hline 0.5-FA30-T & & & 307 & 430 & 0 & 184 & 1,229 \\
\hline $0.5-\mathrm{OPC}-\mathrm{S}$ & & & 311 & 622 & 0 & 0 & 1,245 \\
\hline $0.5-B 40-S$ & & \multirow{5}{*}{$\begin{array}{l}\text { Artificial } \\
\text { seawater }\end{array}$} & 305 & 366 & 244 & 0 & 1,220 \\
\hline $0.5-B 55-S$ & & & 303 & 272 & 333 & 0 & 1,210 \\
\hline $0.5-B 70-S$ & & & 301 & 181 & 421 & 0 & 1,200 \\
\hline $0.5-\mathrm{FA} 10-\mathrm{S}$ & & & 312 & 562 & 0 & 62 & 1,249 \\
\hline $0.5-\mathrm{FA} 30-\mathrm{S}$ & & & 307 & 430 & 0 & 184 & 1,229 \\
\hline 0.7-OPC-Т & \multirow{12}{*}{0.7} & \multirow{7}{*}{$\begin{array}{l}\text { Tap } \\
\text { water }\end{array}$} & 393 & 561 & 0 & 0 & 1,122 \\
\hline 0.7-B40-T & & & 390 & 334 & 223 & 0 & 1,114 \\
\hline 0.7-B55-T & & & 389 & 250 & 306 & 0 & 1,111 \\
\hline 0.7-B70-T & & & 388 & 166 & 388 & 0 & 1,108 \\
\hline $0.7-\mathrm{FA} 10-\mathrm{T}$ & & & 389 & 500 & 0 & 56 & 1,111 \\
\hline $0.7-\mathrm{FA} 30-\mathrm{T}$ & & & 383 & 383 & 0 & 164 & 1,095 \\
\hline 0.7 -OPC-S & & & 393 & 561 & 0 & 0 & 1,122 \\
\hline 0.7-B40-S & & \multirow{5}{*}{$\begin{array}{l}\text { Artificial } \\
\text { seawater }\end{array}$} & 390 & 334 & 223 & 0 & 1,114 \\
\hline 0.7-B55-S & & & 389 & 250 & 306 & 0 & 1,111 \\
\hline 0.7-B70-S & & & 388 & 166 & 388 & 0 & 1,108 \\
\hline $0.7-F A 10-S$ & & & 389 & 500 & 0 & 56 & 1,111 \\
\hline $0.7-\mathrm{FA} 30-\mathrm{S}$ & & & 383 & 383 & 0 & 164 & 1,095 \\
\hline
\end{tabular}

Table 3. Chemical components of artificial seawater.

\begin{tabular}{lcccccc}
\hline Chemicals & $\mathrm{NaCl}$ & $\begin{array}{c}\mathrm{MgCl}_{2}- \\
6 \mathrm{H}_{2} \mathrm{O}\end{array}$ & $\mathrm{Na}_{2} \mathrm{SO}_{4}$ & $\mathrm{CaCl}_{2}$ & $\mathrm{KCl}$ & $\mathrm{NaHCO}_{3}$ \\
\hline $\begin{array}{l}\text { Concentration } \\
(\mathrm{g} / \mathrm{L})\end{array}$ & 24.54 & 11.1 & 4.09 & 1.16 & 0.69 & 0.2 \\
\hline
\end{tabular}

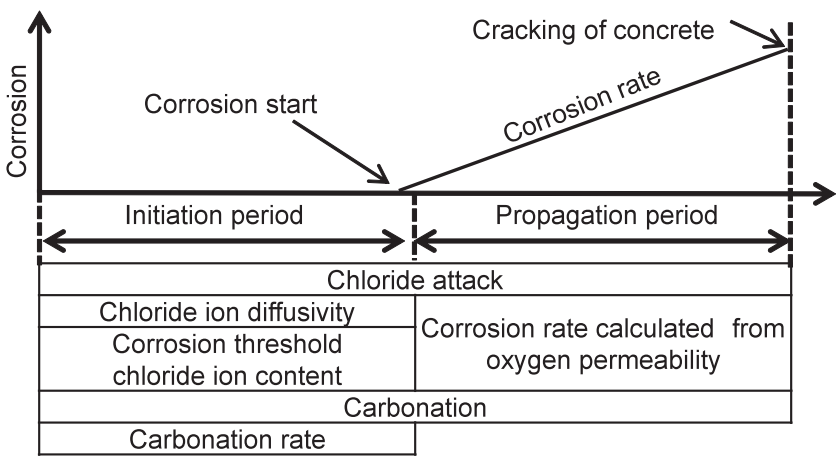

Figure 1. Outline of lifetime prediction.

depths of specimens from the exposure side were determined. Based on those results, the chloride ion diffusivity coefficient was calculated using the following equation, Fick's laws of diffusion:

$$
C(x, t)=C_{0}\left(1-\operatorname{erf}\left(\frac{x}{2 \sqrt{D_{c} \cdot t}}\right)\right)
$$

where $C(x, t)$ is the chloride concentration at any position $x$ at the time $t$ in $\mathrm{kg} / \mathrm{m}^{3}, C_{0}$ is the chloride concentration on the concrete surface in $\mathrm{kg} / \mathrm{m}^{3}, x$ is the distance from the concrete surface in $\mathrm{mm}, t$ is the time in year, erf is the error function, and $D_{c}$ is the diffusion coefficient in $\mathrm{cm}^{2} / y e a r$.

\subsubsection{Corrosion current density of steel bar}

In this article, the mortar specimens were used to evaluate the corrosion phenomena of steel bar in concrete. After curing, the mortar specimens were exposed into accelerated sprayed chamber with $50^{\circ} \mathrm{C}$ of $\mathrm{NaCl}$ solution (3.0 wt.\%). During the testing, the polarization resistance was measured by AC impedance method using high frequency $(10 \mathrm{kHz})$ and low frequency $(10 \mathrm{mHz})$ of alternative current, and corrosion current density was calculated with Stern-Geary constant (Stern \& Geary, 1957) based on the following equation:

$$
I_{\text {corr }}=\frac{K}{R_{c t} \cdot S},
$$

where $I_{\text {corr }}$ is the corrosion current density in $\mu \mathrm{A} / \mathrm{cm}^{2}$, $R_{\mathrm{ct}}$ is the polarization resistance in $\Omega, S$ is the surface area of steel bar that equals to $40.82 \mathrm{~cm}^{2}, K$ is SternGeary constant that equals to $0.0209 \mathrm{~V}$.

\subsubsection{Corrosion threshold chloride ion content}

In this article, mortar specimens were used to determine the corrosion threshold chloride ion content of steel bar in concrete. Chloride ion content in mortar around steel bar was evaluated when the corrosion current density reached $0.2 \mu \mathrm{A} / \mathrm{cm}^{2}$ (CEB Working Party V/4.1, 1997).

\subsubsection{Carbonation rate coefficient}

In this article, the cylinder concrete specimens were used to evaluate carbonation rate coefficient. Specimens were exposed in accelerated carbonation condition $\left(\mathrm{CO}_{2}\right.$ concentration: 5 and 10\%). After 4, 12, and 16 weeks of carbonation, depth was measured using phenolphthalein method (JIS-A-1152). According to JIS-A-1153 carbonation rate, coefficient was evaluated by measured carbonation depth and $V_{t}$ method. Then it is conversed into air environment $\left(\mathrm{CO}_{2}\right.$ concentration: $\left.0.035 \%\right)$ using following equation (Uomoto \& Takada, 1991):

$$
X=(2.804-0.874 \log C) A \sqrt{C \times t},
$$

where $X$ is the carbonation depth, $C$ is the concentration of $\mathrm{CO}_{2}, t$ is the exposure time (year), and $A$ is the carbonation rate coefficient.

\subsubsection{Oxygen permeability and corrosion rate}

In this article, mortar specimens were used to evaluate oxygen permeability. Limit corrosion current density obtained from electrochemical measurement using cathodic polarization curves was used as shown in 
the following equation. The corrosion rate was directly calculated from $i_{\text {lim }}$.

$$
\frac{\partial Q}{\partial t}=-\frac{i_{\lim }}{n \cdot F},
$$

where $\partial Q / \partial t$ is the oxygen permeability in $\mathrm{mol} \cdot \mathrm{cm}^{2} / \mathrm{s}$, $i_{\text {lim }}$ is the limit corrosion current density in $\mathrm{A} / \mathrm{cm}^{2}, n$ is the atomic value $(=4), F$ is the Faraday constant $(=96500 \mathrm{C} / \mathrm{mol})$. In addition to cathodic polarization curves, anodic polarization curves were measured.

\subsubsection{Immobilization rate}

In this article, the quantity of total chloride and watersoluble chloride in mortar/concrete was measured using Japan concrete institute methods (JCl-SC8). In this method, the total chloride was extracted by analysing the chloride ion concentration of $\mathrm{HNO}_{3}$ $(2 \mathrm{~N})$ solution that concrete and mortar melt into, and water-soluble chloride was extracted by analysing the chloride ion concentration from concrete and mortar melt into water. Solutions are in $50^{\circ}$.

\section{DIFFUSIVITY/PENETRABILITY OF MATERIAL}

\subsection{Chloride ion diffusivity}

\subsubsection{Effect of BFS}

Figure 2 shows the comparison between chloride ion diffusivity of concrete mixed with seawater and tap water with BFS. As shown in this figure, chloride ion diffusivity of concrete mixed with seawater was smaller than that with tap water. This might be due to the presence of initial chloride content induced by seawater, and it could result in the decrease of chloride concentration difference between concrete and surrounding seawater.

Also, Figure 3 shows the effect of BFS replacement ratio on chloride ion diffusivity of concrete. As shown in this figure, chloride ion diffusivity of concrete using BFS was smaller than OPC and chloride ion diffusivity of concrete decreases as BFS replacement ratio increases.

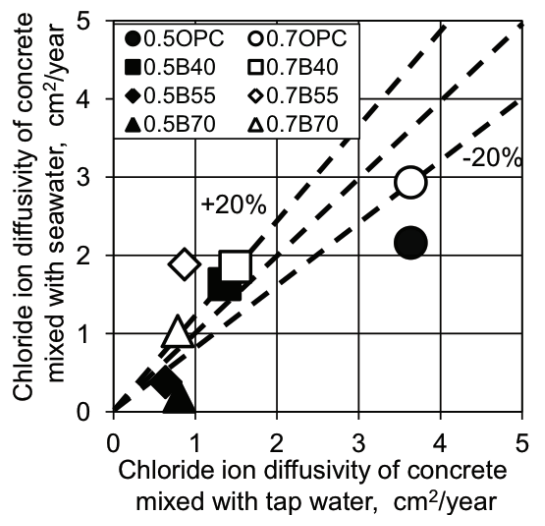

Figure 2. Comparison of mixing water on chloride ion diffusivity with BFS.

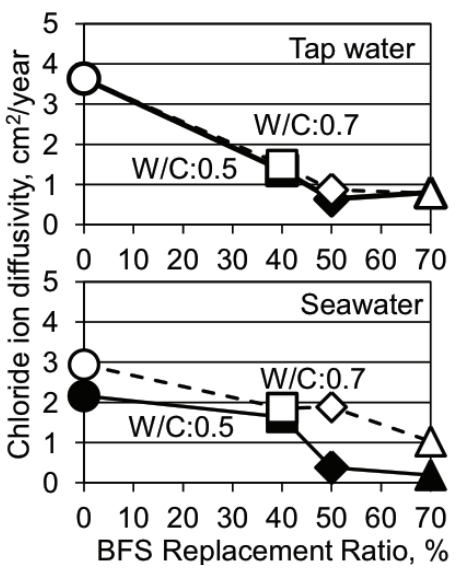

Figure 3. Effect of BFS on chloride ion diffusivity.

\subsubsection{Effect of $F A$}

Figure 4 shows the comparison between chloride ion diffusivity of concrete mixed with seawater and tap water with FA. As shown in this figure, chloride ion diffusivity of concrete mixed with seawater was lower than that with tap water as the same in case of BFS.

Also, Figure 5 shows the effect of FA replacement ratio on chloride ion diffusivity of concrete FA. As shown in this figure, chloride ion diffusivity of concrete using FA was smaller than OPC and chloride ion diffusivity of concrete decreases as BFS replacement ratio increases.

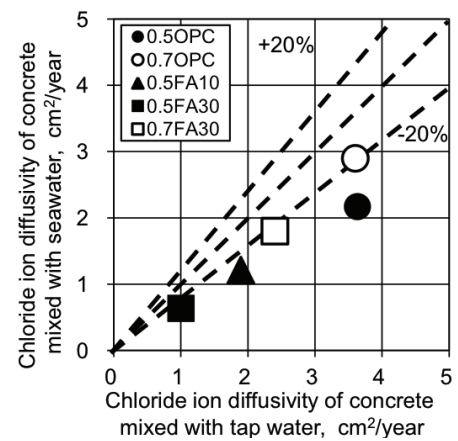

Figure 4. Comparison of mixing water on chloride ion diffusivity with FA.

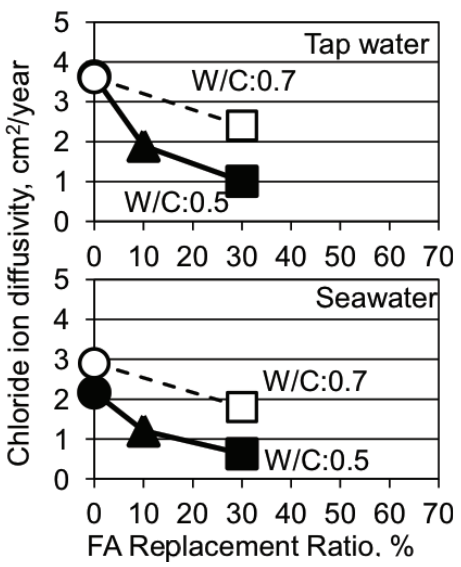

Figure 5. Effect of FA on chloride ion diffusivity. 


\subsection{Carbonation rate}

\subsubsection{Effect of BFS}

Figure 6 shows the comparison between carbonation rate of concrete mixed with seawater and tap water with BFS. As shown in this figure, carbonation rate of concrete mixed with seawater was almost same as that with tap water.

Also, Figure 7 shows the effect of BFS replacement ratio on carbonation rate. As shown in this figure, carbonation rate of concrete using BFS was bigger than OPC and carbonation rate of concrete increased as BFS replacement ratio increased.

\subsubsection{Effect of FA}

Figure 8 shows the comparison between carbonation rate of concrete mixed with seawater and tap water with BFS. As shown in this figure, the carbonation rate of concrete mixed with seawater was almost same as that with tap water.

Also, Figure 9 shows the effect of FA replacement ratio on carbonation rate. As shown in this figure, carbonation rate of concrete using FA was bigger than OPC and carbonation rate of concrete increased as FA replacement ratio increased.

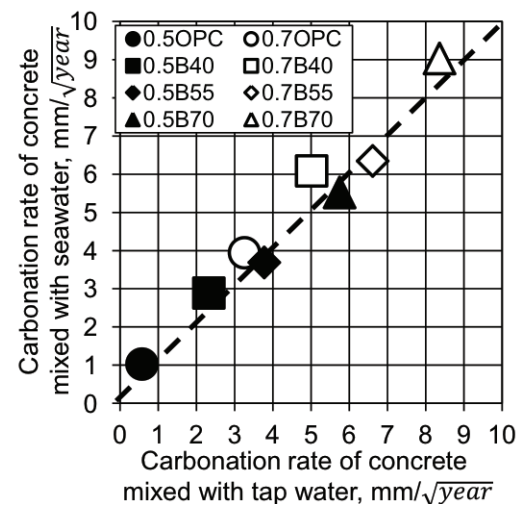

Figure 6. Effect of mixing water on carbonation rate with BFS.

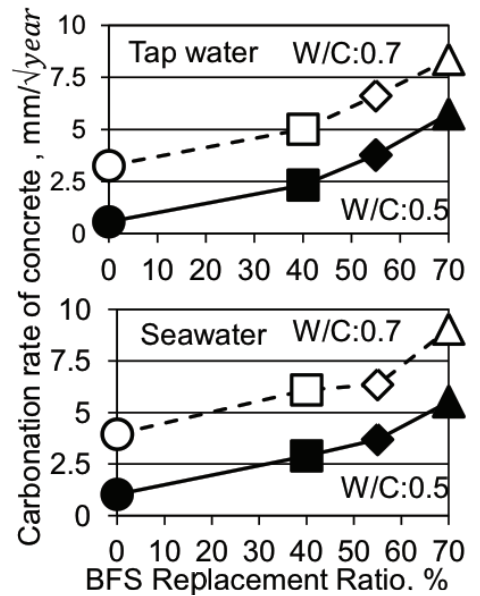

Figure 7. Effect of BFS on carbonation rate.

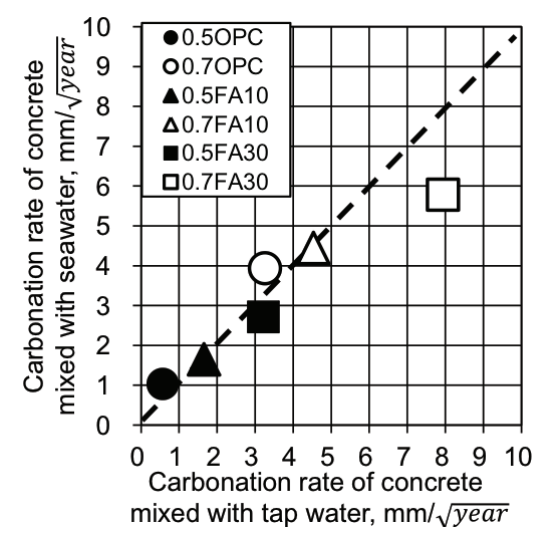

Figure 8. Effect of mixing water on carbonation rate with FA.

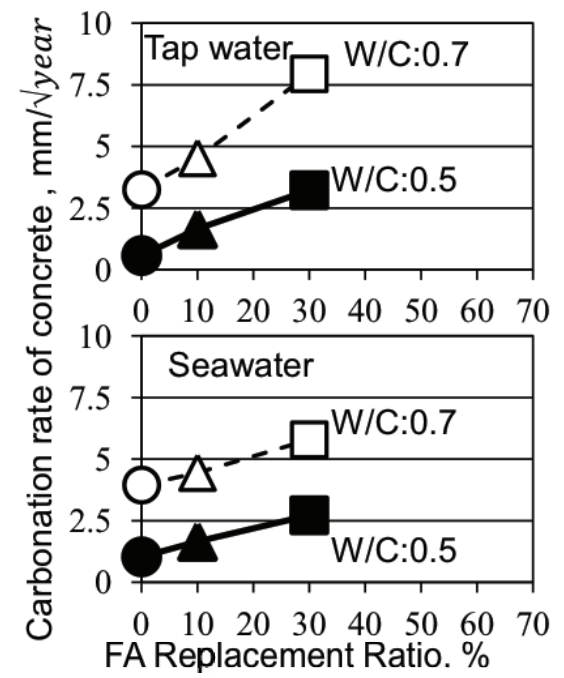

Figure 9. Effect of FA on carbonation rate.

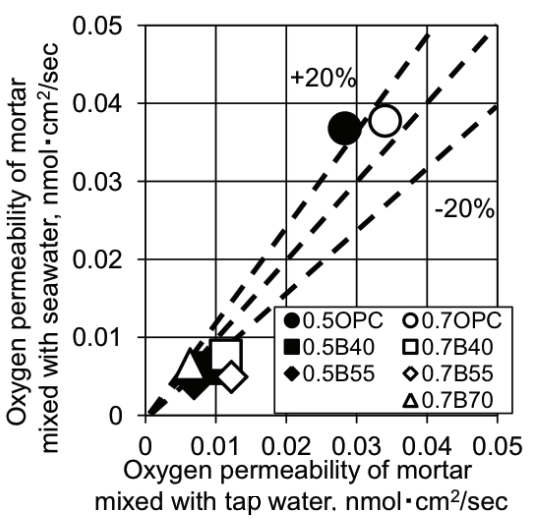

Figure 10. Effect of mixing water on oxygen permeability with BFS.

\subsection{Oxygen permeability}

\subsubsection{Effect of BFS}

Figure 10 shows the comparison between oxygen permeability of concrete mixed with seawater and tap water with BFS. As shown in this figure, oxygen permeability of concrete mixed with seawater was almost same as that with tap water. 


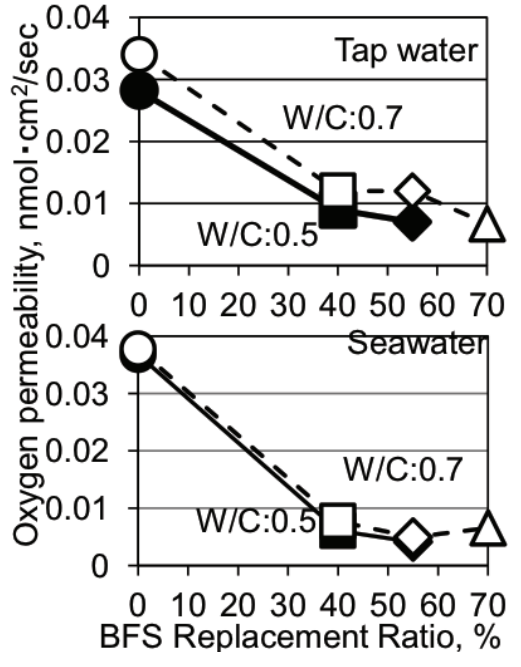

Figure 11. Effect of BFS on oxygen permeability.

Also, Figure 11 shows the effect of BFS replacement ratio on oxygen permeability. As shown in this figure, oxygen permeability of mortar specimen using BFS was smaller than that of OPC specimen and carbonation rate of concrete increased as BFS replacement ratio increased.

\subsubsection{Effect of FA}

Figure 12 shows the comparison between oxygen permeability of mortar mixed with seawater and tap water with FA. As shown in this figure, oxygen permeability of mortar mixed with seawater was almost same as that with tap water.

Also, Figure 13 shows the effect of FA replacement ratio on oxygen permeability. As shown in this figure, oxygen permeability of mortar specimen using FA was smaller than that of OPC specimen, and it decreased as FA replacement ratio increased.

Therefore, it seems that concrete with higher replacement ratio of BFS or FA has better corrosion resistance against chloride attack than OPC concrete.

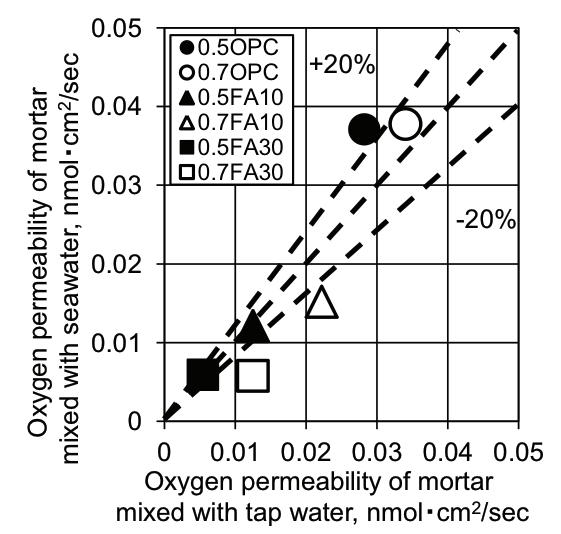

Figure 12. Effect of mixing water on oxygen permeability with FA.

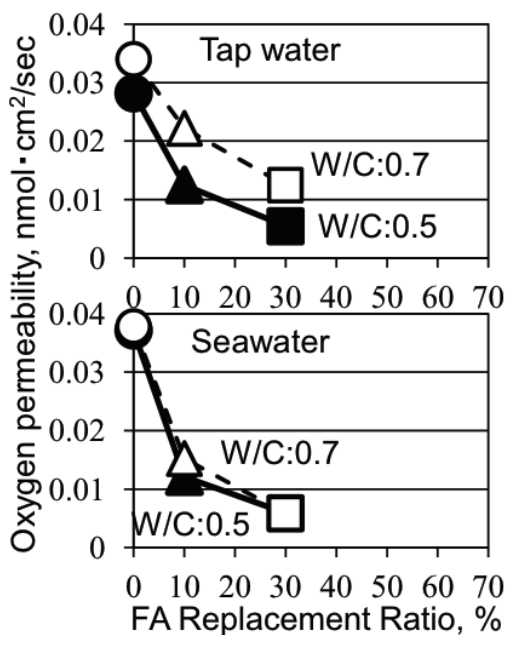

Figure 13. Effect of FA on oxygen permeability.

\section{IMMOBILIZATION OF CHLORIDE ION}

The large amount of chloride ion may cause the corrosion of steel bars in concrete. Especially the quantity of water-soluble chloride is the most important factor in the corrosion of steel bars in concrete, because it destroys directly the passivation film around steel bars. Therefore, it is necessary to clarify the water-soluble chloride content in concrete to understand the corrosion phenomena.

\subsection{Effect of BFS}

Figure 14 shows the chloride ion content in concrete mixed with seawater after 7 days. In this article, total chloride ion content is calculated from mix proportion of concrete. From this figure, water-soluble chloride ion content varied according to replacement ratios of BFS.

Also, Figure 15 shows the influence of BFS replacement ratio on immobilization ratio of chloride ion in concrete. This ratio is calculated from chloride ion content

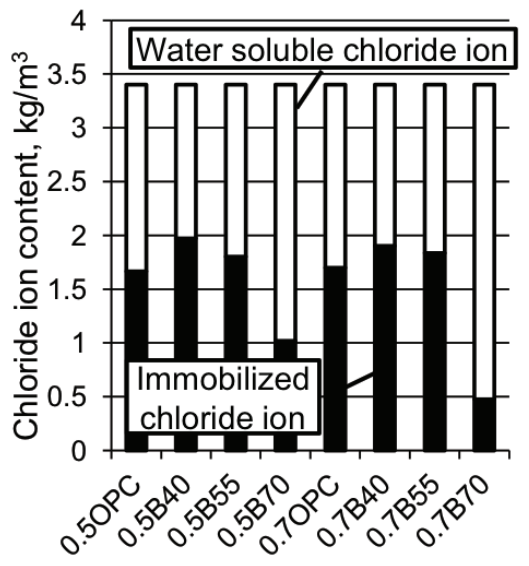

Figure 14. Immobilized and water soluble chloride ion content of concrete specimen with BFS. 


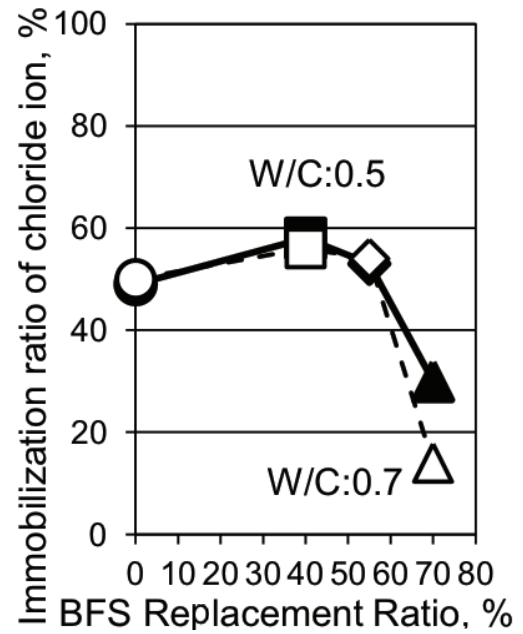

Figure 15. Effect of BFS on immobilization ratio of chloride ion.

shown in Figure 14. The highest immobilization ratio of chloride ion was obtained with BFS $40 \%$ replaced concrete regardless of water cement ratio, and more than $50 \%$ of chloride ion was immobilized in the cement hydrates. From the viewpoint of the immobilization of chloride ion, it is estimated that the $40 \%$ is the most efficient BFS replacement ratio against steel corrosion in concrete mixed with seawater.

\subsection{Effect of FA}

Figure 16 shows the chloride ion content in concrete mixed with seawater after 4 months with the same way in case of BFS. From this figure, the watersoluble chloride ion content varied according to the replacement ratios of FA.

Figure 17 shows the influence of FA replacement ratio on immobilization ratio of chloride ion in concrete calculated from chloride ion content shown in Figure 16. In the case that $\mathrm{W} / \mathrm{C}$ is 0.5 , immobilization ratio of chloride ion of each specimen was almost same.

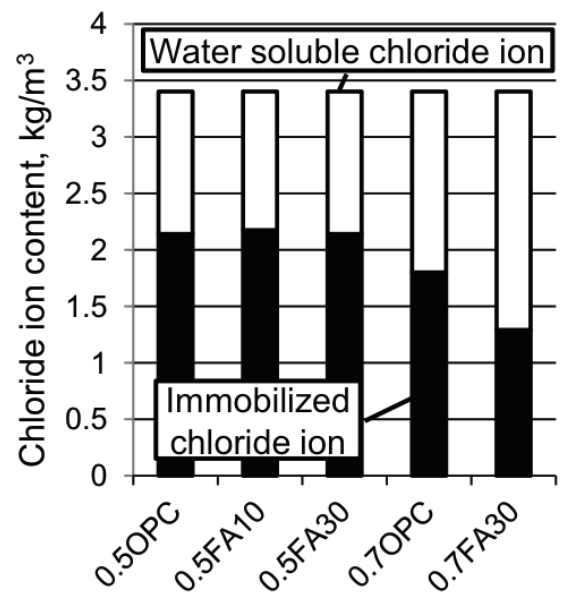

Figure 16. Immobilized and water-soluble chloride ion content of concrete specimen with FA.

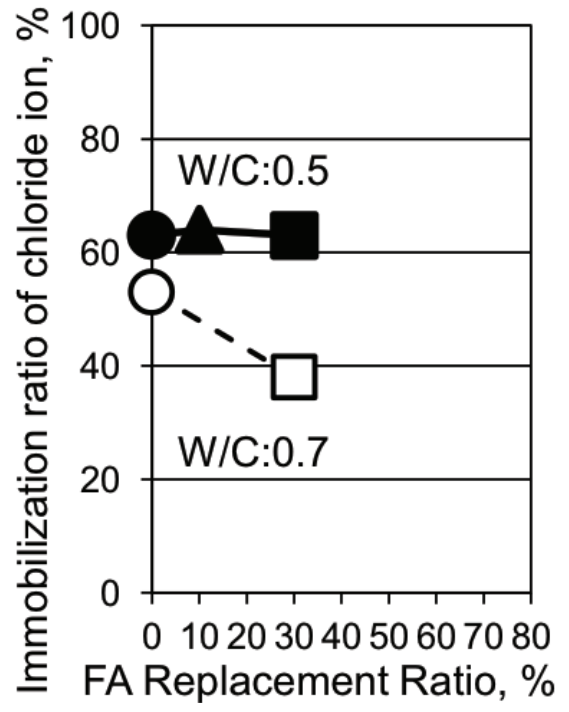

Figure 17. Effect of FA on immobilization ratio of chloride ion.

If $W / C$ is 0.7 , immobilization ratio of chloride ion of $0.7 F A 30$ was smaller than OPC. From the viewpoint of the immobilization of chloride ion, it is estimated that concrete mixed with FA when W/C is 0.5 is efficient against steel corrosion in concrete mixed with seawater.

\section{CORROSION RATES AND CHLORIDE THRESHOLD CONTENTS IN CHLORIDE ATTACK}

To clarify corrosion threshold chloride ion contents, time-dependent changes of corrosion current density were measured. The authors adopted the current density of $0.2 \mu \mathrm{A} / \mathrm{cm}^{2}$ as the threshold current density, which is defined by CEB for structural concrete.

\subsection{Effect of BFS}

Figure 18 shows the time-dependent change of corrosion current density in the case W/C is 0.5 with BFS. The dashed line indicates the value of $0.2 \mu \mathrm{A} /$ $\mathrm{cm}^{2}$, according to the critical value of corrosion current density (CEB Working Party V/4.1, 1997).

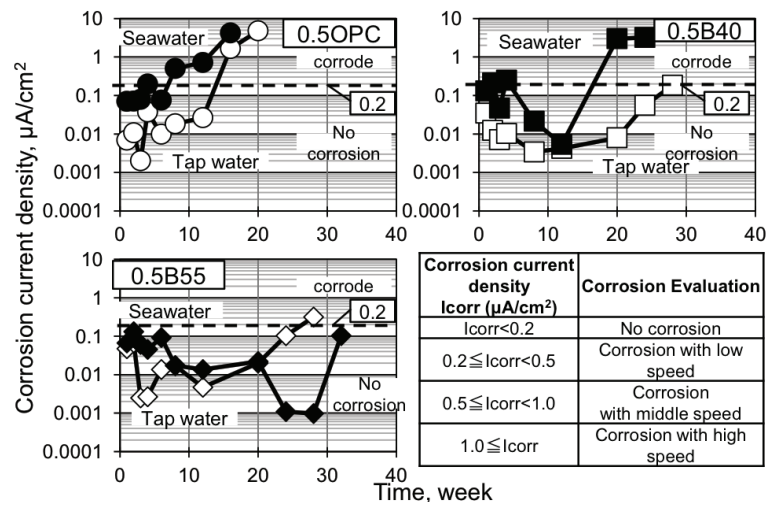

Figure 18. Time dependent change of corrosion current density of specimen with BFS in case W/C is 0.5 . 
The corrosion starting time was steadily increased with increasing of BFS replacement ratio, because increasing of BFS replacement reduced chloride ion diffusivity. Besides, in the case of OPC and BFS $40 \%$ replaced case, duration of the mortar mixed with seawater to reach critical value of corrosion current density $\left(0.2 \mu \mathrm{A} / \mathrm{cm}^{2}\right)$ was shorter than that with tap water. It is considered that initial chloride content induced by seawater as concrete material decreased the duration to reach corrosion threshold chloride content.

On the other hand, BFS 55\% replaced mortar mixed with seawater had almost same resistance against corrosion as that mixed with tap water. It is considered that long duration to reach critical value of corrosion current density and its chloride ion diffusivity was shorter than that with tap water.

Figure 19 shows the corrosion threshold chloride content obtained in this article. As it could be seen, BFS-replaced specimens had smaller corrosion threshold chloride content than OPC specimen. It is highly possible that $\mathrm{Cl}^{-} / \mathrm{OH}$ was increased with increasing of BFS replacement ratio because high BFS replaced cement had low $\mathrm{pH}$. Additionally, the value of BFS $70 \%$ replacement (when $\mathrm{W} / \mathrm{C}=0.7$ ) is less than initial chloride contents (dashed horizontal line shown in Figure 18) induced by concrete mixed with seawater.

It means BFS $70 \%$ replaced concrete mixed with seawater induces corrosion at the initial stage. As a result, in case of OPC, corrosion threshold chloride content was about $5-6 \mathrm{~kg} / \mathrm{m}^{3}$, and in cases of BFS pattern, the value was about $3-4 \mathrm{~kg} / \mathrm{m}^{3}$.

\subsection{Effect of FA}

Figure 20 shows the time-dependent change of corrosion current density in the case W/C is 0.5 with FA. The corrosion starting time was steadily increased with increasing of FA replacement ratio, because increasing of FA replacement-reduced chloride ion diffusivity. Besides, duration of the mortar mixed with seawater to reach critical value of corrosion current density $\left(0.2 \mu \mathrm{A} / \mathrm{cm}^{2}\right)$ was shorter than that with tap water as the same in case of BFS.

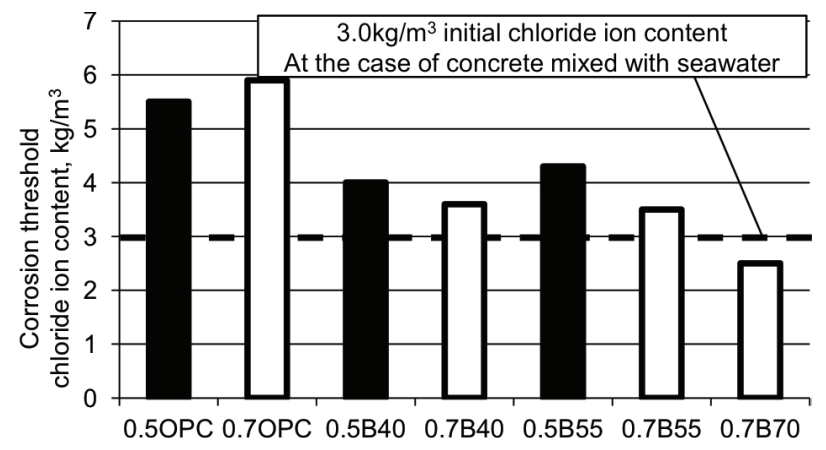

Figure 19. Corrosion threshold chloride ion content in case of BFS.

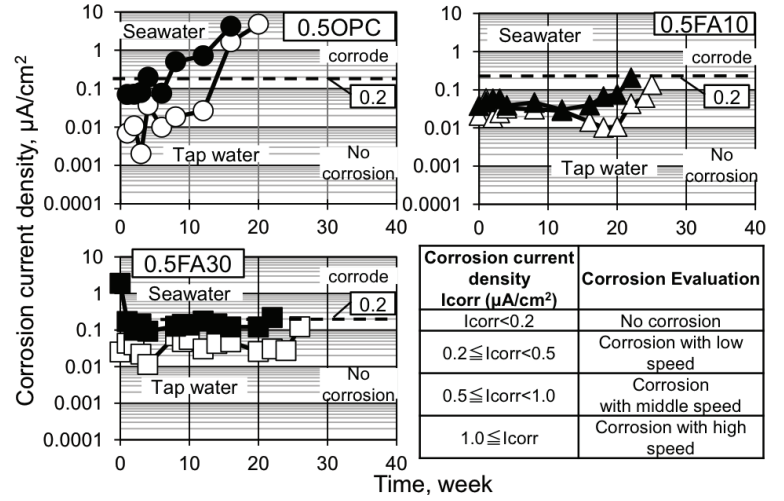

Figure 20. Time-dependent change of corrosion current density in the case with FA in case W/C is 0.5 .

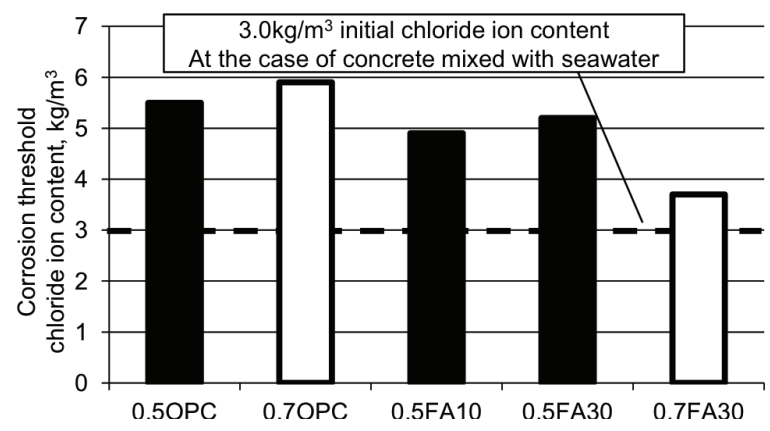

Figure 21. Corrosion threshold chloride ion content in case of FA.

Figure 21 shows the corrosion threshold chloride content obtained in this article. As it could be seen, FA-replaced specimens had smaller corrosion threshold chloride content than OPC specimen as the same in case of BFS. As a result, in cases of FA pattern, the corrosion threshold chloride ion content was about $3-5 \mathrm{~kg} / \mathrm{m}^{3}$.

\section{LIFETIME PREDICTION}

In this section, initiation and propagation periods against chloride attack and the initiation period against carbonation were calculated based on the aforementioned material properties and assumptions.

\subsection{Lifetime prediction against chloride attack}

In this article, lifetime against chloride attack is defined as summation of initiation and propagation period against chloride attack.

For estimation of initiation periods, covering depth, initial chloride ion content, surface chloride ion content, chloride ion diffusivity, and corrosion threshold chloride content are required. Then with Fick's diffusion equation, the periods are calculated when the calculated chloride content is equal to the corrosion threshold chloride content.

For estimation of propagation period, the corrosion rate and the critical amount of corrosion product, 
which generates cracks in cover concrete, should be assumed. Then the periods are calculated when the amount of the corrosion product reaches to the critical value. In this article, amount of the corrosion product was calculated with the following equation (Yokozeki, Motohashi, Okada, \& Tsutsumi, 1997):

$$
\begin{aligned}
& W c r=-1.841 \phi(\phi-8.6661)+145.1 \alpha^{-1.194}, \\
& +3809 A^{-0.8351}+10.60 X-72.30
\end{aligned},
$$

where $W c r$ is the amount of corrosion product around steel bar at the end of propagation period $\left(\mathrm{mg} / \mathrm{cm}^{2}\right), \varphi$ is the creep coefficient, $\alpha$ is the coefficient of thermal expansion (=3.2), $A$ is the corrosion angle $\left(360^{\circ}\right)$, and $X$ is the shape function (covering depth/diameter of steel bar). The value became $53.8 \mathrm{mg} / \mathrm{cm}^{2}$ in the case of $70 \mathrm{~mm}$ of covering depth and $13 \mathrm{~mm}$ of diameter of steel bar.

To calculate lifetime against chloride attack, the environment is defined as submerged zone, and covering depth is defined as $70 \mathrm{~mm}$.

\subsubsection{Effect of BFS}

6.1.1.1 Initiation period against chloride attack

Figure 22 shows the comparison between initiation period of concrete mixed with seawater and tap water with BFS against chloride attack. As shown in this figure, initiation period of concrete mixed with seawater was shorter than that with tap water. It is considered that seawater as mixing water induced initial chloride content, and shortened the duration to reach corrosion threshold chloride ion content. So, only considering initiation period, concrete mixed with seawater with BFS is not suitable.

Also, Figure 23 shows the effect of BFS replacement ratio on initiation period against chloride attack. As shown in this figure, $55 \%$ BFS replaced concrete when $\mathrm{W} / \mathrm{C}$ is 0.5 shows longest initiation period regardless of the type of mixing water.

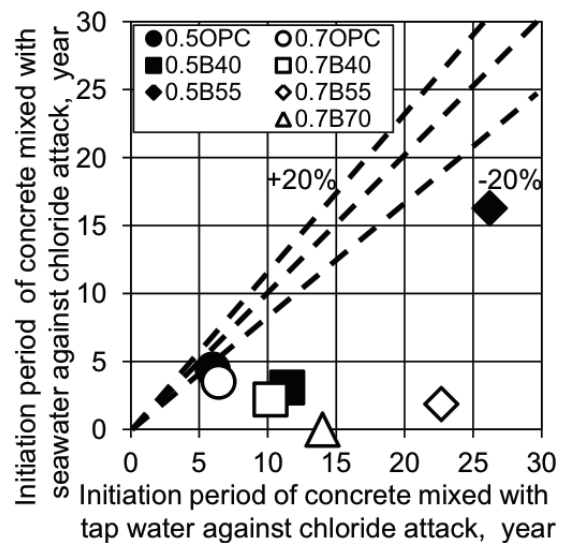

Figure 22. Effect of mixing water on initiation period against chloride attack with BFS.

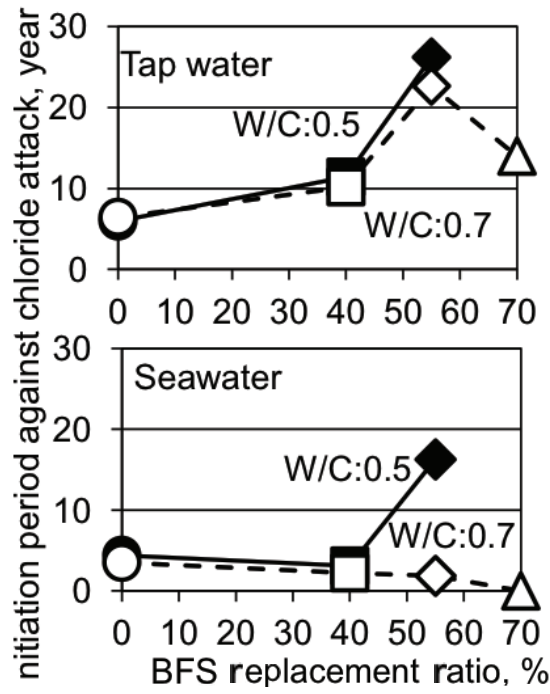

Figure 23. Effect of BFS on initiation period against chloride attack.

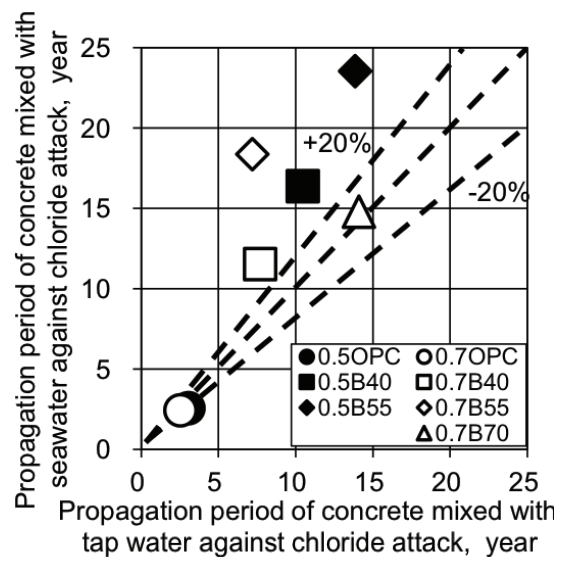

Figure 24. Effect of mixing water on propagation period against chloride attack with BFS.

6.1.1.2 Propagation periods against chloride attack Figure 24 shows the comparison between propagation period of concrete mixed with seawater and tap water with BFS against chloride attack. As shown in this figure, propagation period of concrete mixed with seawater was longer than that with tap water. It is considered that low corrosion rate of concrete mixed with seawater using BFS expanded this period.

Also, Figure 25 shows the effect of BFS replacement ratio on initiation period against chloride attack. As shown in this figure, 55\% BFS replaced concrete shows longest initiation period regardless of type of mixing water.

\subsubsection{Lifetime against chloride attack} Using results of initiation period and propagation period against chloride attack, the lifetime, summation of initiation and propagation period, was investigated. The results are shown in Figures 26 and 27 and Table 4. 


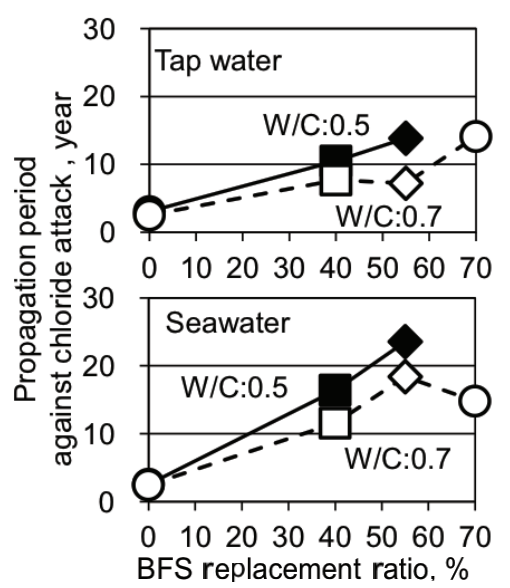

Figure 25. Effect of BFS on propagation period against chloride attack.

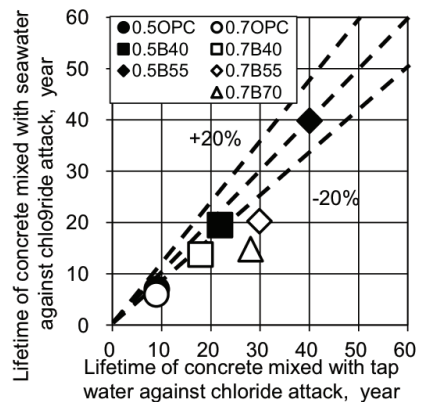

Figure 26. Effect of mixing water on lifetime against chloride attack with BFS.

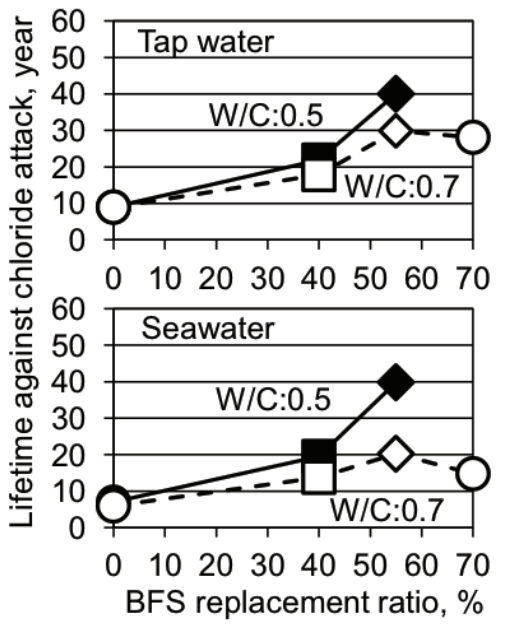

Figure 27. Effect of BFS on lifetime against chloride attack.
From these results, only considering initiation period, concrete mixed with seawater using BFS may not be suitable. However, considering the summation of initiation and propagation periods as lifetime, concrete mixed with seawater had almost same or slightly shorter lifetime than that mixed with tap water. Especially, in the case of BFS $55 \%$ concrete when W/C is 0.5 , the lifetime difference between seawater and tap water mixed concrete had minimum value. And the lifetime of concrete mixed with seawater was about 40 years.

\subsubsection{Effect of $F A$}

6.1.2.1 Initiation period against chloride attack

Figure 28 shows the comparison between initiation period of concrete mixed with seawater and tap water with FA against chloride attack. As shown in this figure, initiation period of concrete mixed with seawater was shorter than that with tap water. So, only considering initiation period, concrete mixed with seawater with FA is not suitable as the same in case of BFS.

Also, Figure 29 shows the effect of FA replacement ratio on initiation period against chloride attack. As shown in this figure, 30\% FA replaced concrete when $\mathrm{W} / \mathrm{C}$ is 0.5 showed longest initiation period regardless of type of mixing water.

\subsubsection{Propagation period}

Figure 30 shows the comparison between propagation period of concrete mixed with seawater and tap water with FA against chloride attack. As shown in this figure, propagation period of concrete mixed with seawater

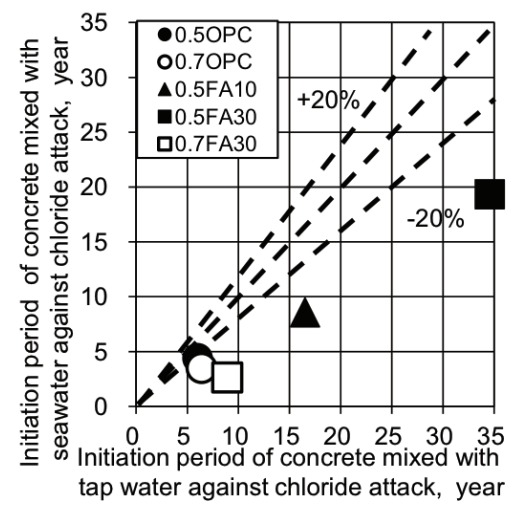

Figure 28. Effect of mixing water on initiation period against chloride attack with FA.

Table 4. Lifetime against chloride attack with BFS.

\begin{tabular}{|c|c|c|c|c|c|c|c|c|c|}
\hline \multirow{3}{*}{ Mixing water } & \multicolumn{3}{|c|}{ Initiation period } & \multicolumn{3}{|c|}{ Propagation period } & \multicolumn{3}{|c|}{ Lifetime(Total) } \\
\hline & \multicolumn{2}{|c|}{ Duration (year) } & \multirow[t]{2}{*}{ Best mix } & \multicolumn{2}{|c|}{ Duration (year) } & \multirow[t]{2}{*}{ Best mix } & \multicolumn{2}{|c|}{ Duration (year) } & \multirow[t]{2}{*}{ Best mix } \\
\hline & Ave. & 13.8 & & Ave. & 8.4 & & Ave. & 22.3 & \\
\hline \multirow[t]{3}{*}{ Tap water } & Max. & 26.2 & 0.5 B55 & Max. & 14.1 & 0.5 B55 & Max. & 40.1 & 0.5 B55 \\
\hline & Min. & 6.0 & & Min. & 2.5 & & Min. & 8.9 & \\
\hline & Ave. & 4.5 & & Ave. & 12.8 & & Ave. & 17.3 & \\
\hline \multirow[t]{2}{*}{ Seawater } & Max. & 16.3 & 0.5 B55 & Max. & 23.5 & 0.5 B55 & Max. & 39.9 & 0.5 B55 \\
\hline & Min. & 0 & & Min. & 2.4 & & Min. & 5.9 & \\
\hline
\end{tabular}




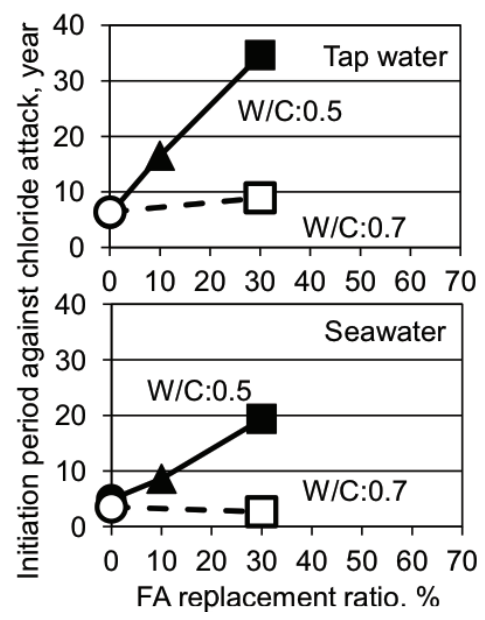

Figure 29. Effect of FA on initiation period against chloride attack.

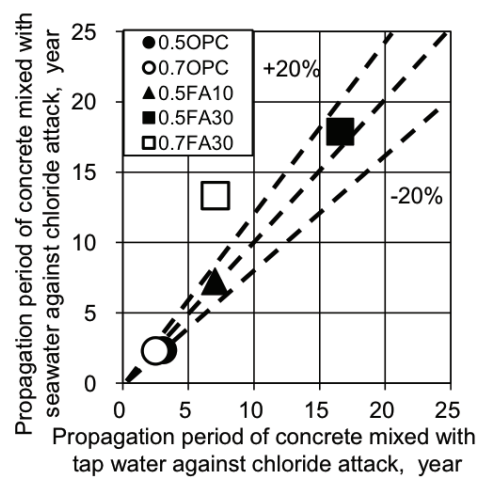

Figure 30. Effect of mixing water on propagation period against chloride attack with FA.

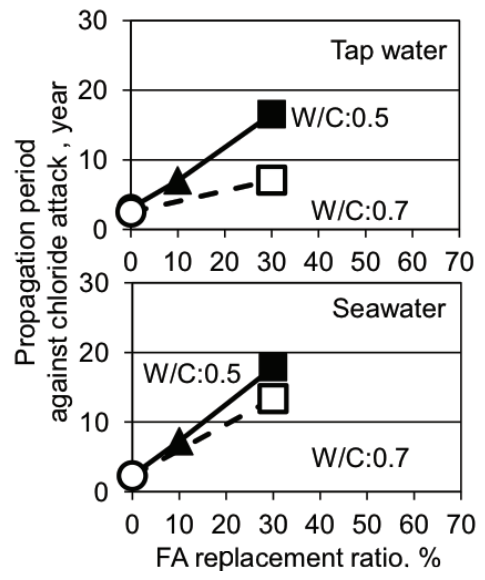

Figure 31. Effect of FA on propagation period against chloride attack

was longer than that with tap water. It is considered that low corrosion rate of concrete mixed with seawater using FA expanded this period.

Also, Figure 31 shows the effect of FA replacement ratio on initiation period against chloride attack. As shown in this figure, $55 \%$ BFS-replaced concrete shows longest initiation period regardless of the type of mixing water.
6.1.2.3 Lifetime

Using results of initiation period and propagation period against chloride attack, the lifetime including initiation and propagation was investigated. The results are shown in Figures 32 and 33 and Table 5.

From these results, only considering initiation period, concrete mixed with seawater using FA may not be suitable. However, considering the summation of initiation and propagation periods as lifetime, concrete mixed with seawater had almost same or slightly shorter lifetime than that mixed with tap water. Especially, in the case of FA 30\% concrete (0.5FA30), the lifetime of concrete mixed with seawater was about 40 years.

\subsection{Lifetime prediction against carbonation}

In this article, lifetime against carbonation was defined as initiation period against carbonation.

For estimation of initiation period, covering depth and carbonation rate coefficient are required. Then

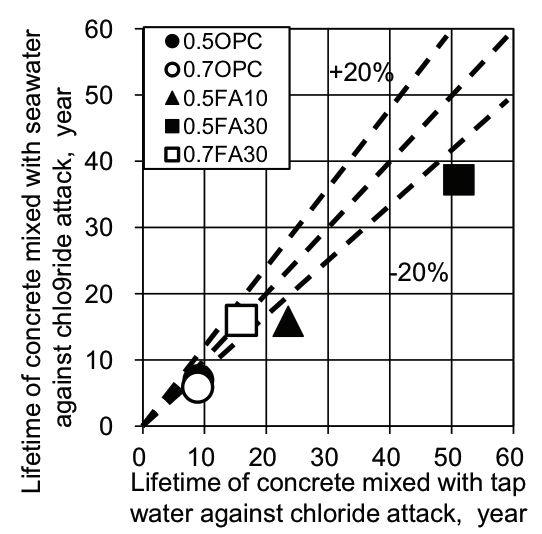

Figure 32. Effect of mixing water on lifetime against chloride attack with FA.

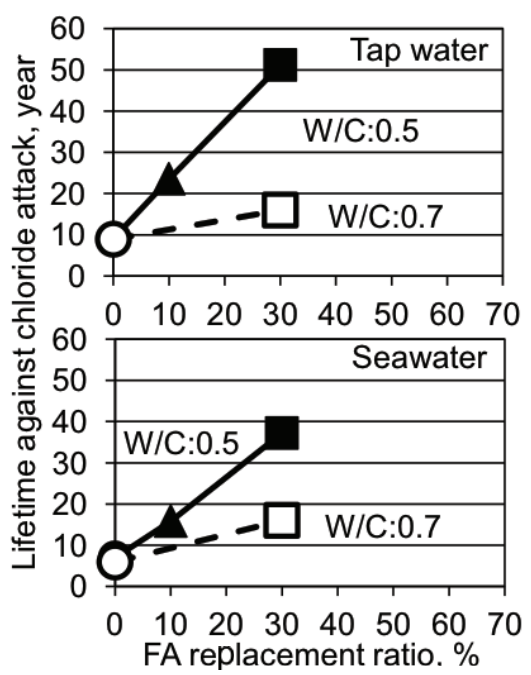

Figure 33. Effect of FA on lifetime against chloride attack. 
Table 5. Lifetime against chloride attack with FA.

\begin{tabular}{|c|c|c|c|c|c|c|c|c|c|}
\hline \multirow{3}{*}{ Mixing water } & \multicolumn{3}{|c|}{ Initiation period } & \multicolumn{3}{|c|}{ Propagation period } & \multicolumn{3}{|c|}{ Lifetime(Total) } \\
\hline & \multicolumn{2}{|c|}{ Duration (year) } & \multirow[t]{2}{*}{ Best mix } & \multicolumn{2}{|c|}{ Duration (year) } & \multirow[t]{2}{*}{ Best mix } & \multicolumn{2}{|c|}{ Duration (year) } & \multirow[t]{2}{*}{ Best mix } \\
\hline & Ave. & 14.5 & & Ave. & 7.2 & & Ave. & 21.7 & \\
\hline \multirow[t]{3}{*}{ Tap water } & Max. & 34.6 & 0.5 FA30 & Max. & 16.6 & 0.5 FA30 & Max. & 51.2 & 0.5 FA30 \\
\hline & Min. & 6.0 & & Min. & 2.5 & & Min. & 8.9 & \\
\hline & Ave. & 7.8 & & Ave. & 8.6 & & Ave. & 16.4 & \\
\hline \multirow[t]{2}{*}{ Seawater } & Max. & 19.3 & 0.5 FA30 & Max. & 17.9 & 0.5 FA30 & Max. & 37.2 & 0.5 FA30 \\
\hline & Min. & 3.5 & & Min. & 2.4 & & Min. & 5.9 & \\
\hline
\end{tabular}

the periods are calculated when carbonation depth reaches the covering depth with $\sqrt{ } t$ method.

To calculate lifetime against carbonation, the environment is defined as natural environment $\left(\mathrm{CO}_{2}\right.$ concentration: $0.0315 \%$ ), and covering depth is defined as $30 \mathrm{~mm}$.

\subsubsection{Effect of BFS}

Figure 34 shows the comparison between lifetime of concrete mixed with seawater and tap water with BFS against carbonation. As shown in this figure, lifetime of concrete mixed with seawater against carbonation was almost same as that with tap water.

Also, Figure 35 shows the effect of BFS replacement ratio on lifetime against carbonation. Lifetime against carbonation decreased as BFS replacement ratio increased. In case W/C is 0.5 regardless of type of mixing water, initiation periods of OPC and BFS $40 \%$ concrete were longer than 100 years.

\subsubsection{Effect of FA}

Figure 36 shows the comparison between lifetime of concrete mixed with seawater and tap water with FA against carbonation. As shown in this figure, lifetime of concrete mixed with seawater was almost same as that with tap water.

Also, Figure 37 shows the effect of FA replacement ratio on lifetime against carbonation. Lifetime against carbonation decreases as FA replacement ratio

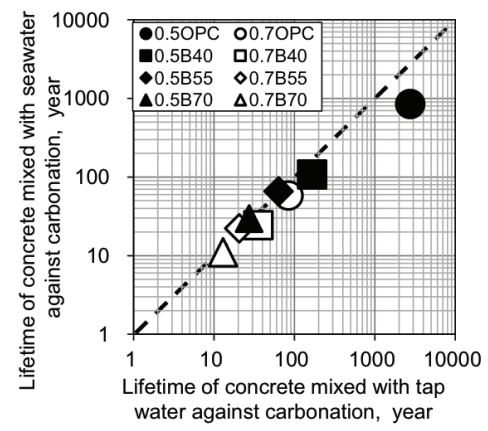

Figure 34. Effect of mixing water on lifetime against carbonation with BFS.

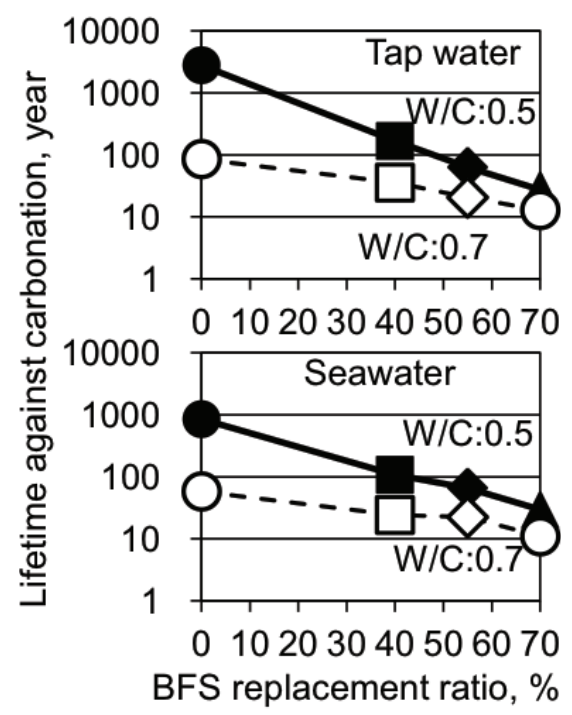

Figure 35. Effect of BFS on lifetime against carbonation.

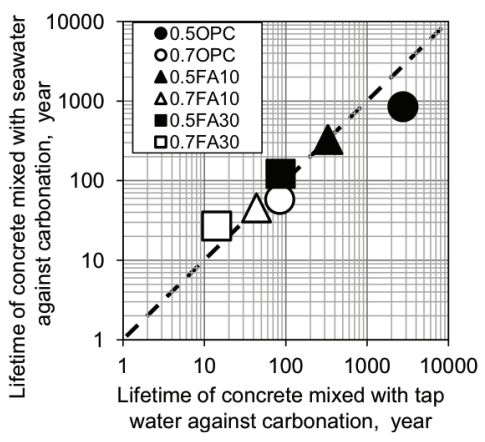

Figure 36. Effect of mixing water on lifetime against carbonation with FA.

increases. In case W/C is 0.5 regardless of type of mixing water, initiation periods of concrete were longer than 100 years.

\section{EFFECT OF BFS AND FA WITH SEAWATER}

Considering lifetime against chloride attack, maximum lifetime of concrete mixed with seawater using BFS and FA is almost same and 40 years, almost four times as long as that using OPC. 


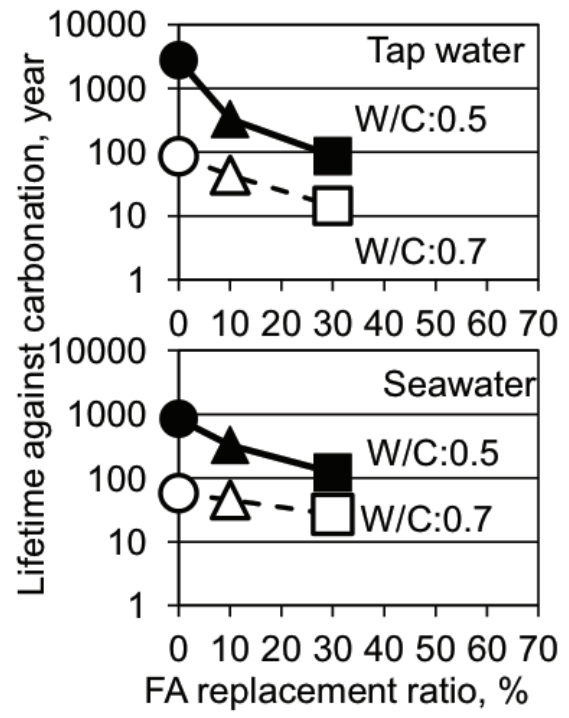

Figure 37. Effect of FA on lifetime against carbonation.

Therefore, there is possibility of usage of concrete mixed with BFS or FA against chloride attack.

Considering lifetime against carbonation, maximum lifetime of concrete mixed with seawater using BFS and FA is almost 100 years, longer than 50 years (general lifetime of concrete structure). Although their value is shorter than that using OPC, there is possibility of usage of concrete mixed with BFS and FA against carbonation if the structure does not need longer lifetime.

\section{CONCLUSIONS}

In this article, the following conclusions were obtained.

\subsection{Main conclusions}

The most important conclusion is "In some conditions, using seawater as mixing water in RC is possible", and the conditions are as follows:

(1) In performance-based design and the lifetime determined by chloride attack and propagation periods, it is possible to use seawater and if with BFS or FA it is much better than with OPC.

(2) In performance-based design and the lifetime determined by carbonation and in this case initiation period, it is possible to use seawater. In this case, maximum lifetime of concrete mixed with seawater using BFS and FA against carbonation obtained in this article are longer than 100 years. Although their values are not better than that using OPC, there is possibility of usage of concrete mixed with BFS and FA against carbonation if the structure does not need so long lifetime.

\subsection{Subconclusions about influence of BFS and FA}

8.2.1 Diffusivity/permeability of materials

Usage of BFS or FA for concrete can reduce chloride ion diffusivity and oxygen permeability, but increases carbonation rate of concrete.

8.2.2 Corrosion rates of steel bars

Usage of BFS or FA for concrete can decrease corrosion rate of steel bar owing to their effect to reduce oxygen permeability.

8.2.3 Corrosion threshold chloride ion contents

Usage of BFS or FA for concrete can decrease corrosion threshold chloride ion contents of steel bar in concrete because $\mathrm{pH}$ of concrete decreases.

\subsubsection{Lifetime}

Usage of BFS or FA for concrete can expand lifetime of concrete against chloride attack.

On the other hand, it can shorten lifetime of concrete against carbonation.

\subsection{Condition against the usage of seawater}

Condition with the disadvantage of usage of seawater is the condition where lifetime is defined as initiation period against chloride attack.

For example, initiation period against chloride attack of the BFS $70 \%$ replaced concrete when W/C is 0.7 was 0 year, and that of $F A 30 \%$ replaced concrete when W/C is 0.7 is about 2 years.

\section{REFERENCES}

CEB Working Party V/4.1. (1997). Strategies for testing and assessment of concrete structure affected by reinforcement corrosion (draft 4). BBRI-CSTC-WTCB.

Shickomano, I. A. (1997). Assessment of water resources and water availability in the world. Geneva, Switzerland: SEI and WMO.

Stern, M., \& Geary, A. L. (1957). Electrochemical polarization: I. A theoretical analysis of the shape of polarization curves. Journals of the Electrochemical Society, 104(1), 56-63.

Uomoto, T., \& Takada, Y. (1991). Influence of concentration carbon dioxide on carbonation ratio of concrete. Production Study (Tokyo University), 43(6), 289-292.

Yokozeki, K., Motohashi, K., Okada, K., \& Tsutsumi, T. (1997). A rational model to predict service life of RC structures in marine environment. Forth CANMET/ACI International Conference on Durability of Concrete. pp. 777-796. 